The paper considers the process of hydrate-paraffin deposits formation in oil wells. Due to the research with the author's specially designed laboratory equipment an experimental installation containing a technological unit and an information-measuring system, the most favorable pressure-temperature conditions of hydrate formation in a wide range of pressure (0.1-120 MPa) and temperature (from -20 to $+80^{\circ} \mathrm{C}$ ) were determined. The experimental results made it possible to determine the conditions required for hydrate deposits and iron ( $\mathrm{Fe})$ oxides in the range of temperature from -15 to $+60^{\circ} \mathrm{C}$ and pressure from 0 to $60 \mathrm{MPa}$. These results are confirmed by thermodynamic calculations of the oil-gas-hydrate phase equilibria in the annulus of the well. Data processing was performed using the methods of correlation, dispersion and regression analysis, which allowed comparing the processes of hydrates and iron (Fe) oxides formation in the annulus of oil wells. The results of the study can be used to prevent and eliminate hydrate-paraffin plugs in the dozonhole equipment of oil wells, and also to determine the operation mode of the well for long-term operation of the downhole equipment without complications, accidents and stops for repair works, which reduces downtime

Keywords: hydrate-paraffin formation, iron oxides, tubing, casing, well

How to Cite: Liashenko, A., Makarenko, V., Vynnykov, Y., Petrash, O. (2021). Oil wells hydrate formation regularities. Eastern-European Journal of Enterprise Technologies, 3 (6 (111)), 19-24. doi: https://doi.org/10.15587/1729-4061.2021.233511
UDC 553.982.239

DOI: $10.15587 / 1729-4061.2021 .233511$

\section{OIL WELLS HYDRATE FORMATION REGULARITIES}

Anna Liashenko Corresponding author Senior Lecturer*

E-mail: anliashenko14@gmail.com

Valeriy Makarenko Doctor of Technical Sciences, Professor* Yuriy Vynnkov Doctor of Technical Sciences, Professor* Oleksandr Petrash $\mathrm{PhD}$, Associate Professor*

*Department of Oil and

Gas Engineering and Technology National University «Yuri Kondratyuk Poltava Polytechnic» Pershotravnevyi ave., 24, Poltava, Ukraine, 36011

\section{Introduction}

Oil production at the fields is accompanied by intense hydrate-paraffin formation in the tubing and the intertube space (between the outer surface of the tubing and the inner part of the casing). To eliminate it, oil and gas companies spend significant labor, material and financial resources.

It is known [1-3] that one of the complications of the oil production process is the deposition of gas hydrates and paraffins on the surface of tubing and casing of wells. This phenomenon leads to a decrease in the effective diameter and complicates the operation of pipelines and reservoirs, significantly reducing oil production (20\%) and increasing electricity consumption during oil pumping (10-15\%). Methods of removing these deposits on the surface of underground equipment and surface oil transportation and storage systems (oil gathering systems, separation and stabilization units, etc.) can be improved in two directions: 1) carrying out organizational and technical measures to prevent the formation of deposits; 2) cleaning the surface of the equipment from hydrate-paraffin deposits.

To prevent the formation of hydrate-paraffin deposits, some methods have been proposed, such as the use of special coatings on the inner surface of pipes, introduction of various chemical reagents into the pumped flow, ultrasonic treatment, magnetic treatment, etc. [4]. These methods have been studied mainly in terms of using them in industrial conditions and have received some application. However, in many oil fields, these methods are technically difficult to implement and economically impractical. Therefore, they are usually limited to cleaning measures.
To select the optimal method of preventing hydrate formation, it is necessary to conduct experiments to study the conditions, modes, zones and patterns of these deposits in the tubing and the annulus of oil wells. Only by clarifying the picture of physical mechanisms and the specifics of the formation of these depositss, it is possible to successfully develop new or improve existing effective technologies for the prevention and treatment of complicated oil wells. All these measures help to increase the corrosion resistance of underground downhole equipment.

\section{Literature review and problem statement}

In [5], it was shown that hydrates and iron $(\mathrm{Fe})$ oxides significantly reduce the corrosion resistance of downhole equipment (casing and tubing, frame and individual units of centrifugal pumps, sucker-rod pumping units, etc.). These factors contribute to the formation of resin-paraffin plugs in the annulus, which reduces the inter-cleaning period of wells. A number of theoretical papers are devoted to the problem of hydrate formations in the annular intertube space of oil wells, but their results are not confirmed by experimental and industrial data. Thus, in $[6,7]$, the influence of various factors on the processes of hydrate formation in the tubing of oil production wells was analyzed. Methods for combating the effects of hydrate-paraffin deposits [8] and measures for preventing hydrate-paraffin formations [9] were proposed. In [10], the explanation of physical mechanisms and specific features of hydrate formation in tubing pipes is given. However, there is a lack of results of field tests on real models, which would adequately reflect the physical 
and thermodynamic processes occurring in the annulus of wells during oil production. This factor does not allow developing effective technological methods and organizational and technical measures to prevent and reduce the likelihood of hydrate formation. It is known that these deposits are corrosive to the surface of the casing and tubing in the annular space of oil wells.

As follows from [11], deposits are sparingly soluble in petroleum solvents (gasoline, kerosene, diesel fuel, etc.) due to the high content of refractory paraffins. The solubility of the oil conglomerate increases sharply at temperatures close to the melting point of paraffin $\left(50-60{ }^{\circ} \mathrm{C}\right)$.

For preventing clogging and removing hydrate-paraffin deposits, the following methods are mainly used in the world practice:

- washing wells with inhibitors or chemical reagents and hot water (hydrochemical method) [12-14];

- using scraper tools (mechanical method) [15];

- using lined tubing by applying granular glass or epoxy resin to their inner surface [9];

- using bactericidal protection [9];

- using magnetic protection methods [3];

- using special electric heaters, which contain, for example, a tubular body with heating elements arranged in a spiral on its surface. The heater is lowered into the column and voltage is applied to it, the thermal energy of the heater is transferred to the hydrates, which are destroyed, and solidified paraffin deposits in the tubing and melts them [15];

- using direct electric heating of wells with special electrical installations using tubing and casing as a heating element [16].

The lack of results of field tests on real models, which would adequately reflect the physical and thermodynamic processes occurring in the annulus during oil production, does not allow developing effective technological methods and organizational and technical measures to prevent and reduce the likelihood of hydrate formation, corrosive to the surface of casing and tubing in the annular space of oil wells.

All this suggests that an important component of modern research and development is to conduct appropriate experimental work, followed by processing the data obtained. In particular, to substantiate the optimal method of preventing hydrate formation, it is advisable to investigate the conditions, zones and patterns of these deposits in the tubing and the annulus of oil wells. Only by clarifying the picture of physical mechanisms and the specifics of the formation of these formations, it is possible to successfully develop new or improve existing technologies for the prevention and treatment of complicated oil wells, providing increased corrosion resistance of underground well equipment.

\section{The aim and objectives of the study}

The aim of the work is to determine the patterns of the hydrate formation process under conditions close to the environment of oil wells. This will make it possible to reflect the physical and thermodynamic processes occurring in the annulus of wells during oil production. The results of the study open up practical possibilities for appropriate adjustment of the well conditions to prevent hydrate plugs in it and increase the durability of the equipment.
To achieve the aim, the following objectives were accomplished:

- to develop an experimental installation that can fully simulate the conditions hydrate formation and iron oxides to real well processes;

- to determine the conditions necessary for hydrate formation and iron oxides in different temperature and pressure ranges.

\section{Materials and methods of research}

\section{1. Equipment and materials used in the experiment}

As is known from the practice [3, 8], in real conditions of oil production and preparation in the fields, there are mixtures of hydrocarbon (oil) gases, including $\mathrm{CO}_{2}, \mathrm{H}_{2}$, $\mathrm{N}_{2}, \mathrm{H}_{2} \mathrm{~S}$. These components form mixed hydrates, the composition of which varies depending on pressure and temperature. The form of hydrates also depends on the formation conditions: in a turbulent flow, it is a mass similar to compressed wet snow, and in a laminar flow - crystals of various modifications.

Having a high sorption capacity, hydrates are actively covered with a film of liquid and solid hydrocarbons (resins, asphaltenes, paraffins, salts, mechanical impurities). These compounds strengthen the hydrates and increase their adhesive properties, i.e. the ability to adhere to the walls of the equipment.

Conditions for hydrate formation significantly depend on the gas composition. From the components of petroleum gases, hydrates form nitrogen, hydrogen sulfide, carbon dioxide, methane, ethane, hydrogen, propane and isobutane. The gases of oil fields contain heavy gas fractions. Below Tables 1, 2 present the average statistical data on the composition of pumped oil, water-oil mixture and associated gas, taken from the productive layers of the oil field of the Poltava region (Ukraine).

Table 1

Chemical composition of oil

\begin{tabular}{|c|c|}
\hline \multicolumn{2}{|c|}{ Chemical composition of oil (mol.\%): } \\
\hline carbon dioxide & traces \\
\hline Nitrogen & traces \\
\hline Methane & 0.37 \\
\hline Ethane & 0.41 \\
\hline Propane & 3.43 \\
\hline Isobutane & 1.99 \\
\hline n-butane & 5.58 \\
\hline Isopentane & 2.87 \\
\hline n-pentane & 4.17 \\
\hline residue (hexane + higher) & 81.18 \\
\hline molecular weight of degassed oil & 197.14 \\
\hline molecular weight of the residue & 229.07 \\
\hline
\end{tabular}

In addition, the physical parameters of this reservoir oil are given in Table 2 .

For a detailed study of hydrate formations and iron oxides in the annulus of the oil well, experiments were conducted on the author's specially designed laboratory equipment an experimental installation containing a technological unit and an information-measuring system. 
Table 2

Physical parameters of water-oil mixture and associated gas

\begin{tabular}{|c|c|}
\hline oil and gas saturation pressure, $\mathrm{kgf} / \mathrm{cm}$ & 122.1 \\
\hline gas content, $\mathrm{m}^{3} / \mathrm{t}$ at $20^{\circ} \mathrm{C}$ & 86.43 \\
\hline $\mathrm{m}^{3} / \mathrm{m}^{3}$ at $20^{\circ} \mathrm{C}$ & 74.24 \\
\hline volume ratio & 1.23 \\
\hline oil viscosity, cp & 1.45 \\
\hline oil density, $\mathrm{g} / \mathrm{cm}^{3}$ & 0.749 \\
\hline compressibility ratio, $1 / \mathrm{atm} \cdot 10^{-5}$ & 12.22 \\
\hline \multicolumn{2}{|l|}{ Fluid composition: } \\
\hline water content, vol. \% & 25 \\
\hline mechanical impurities, mg/l & 280 \\
\hline \multicolumn{2}{|c|}{ Chemical composition of associated water, mg/l: } \\
\hline $\mathrm{Cl}^{-}$ & 9,000 \\
\hline $\mathrm{HCO}_{3}^{-}$ & 400 \\
\hline $\mathrm{SO}_{4}^{2-}$ & up to 5 \\
\hline $\mathrm{Ca}^{2+}$ & 600 \\
\hline $\mathrm{Mg}^{2+}$ & 110 \\
\hline $\mathrm{Na}^{2+}, \mathrm{K}^{+}$ & 7,500 \\
\hline $\mathrm{H}_{2} \mathrm{~S}$ & 0.5 \\
\hline $\mathrm{CO}_{2}$ & 50 \\
\hline $\mathrm{O}_{2}$ & 0.2 \\
\hline Total mineralization, g/l & 16 \\
\hline $\mathrm{pH}$ & 7.2 \\
\hline Associated gas $\mathrm{CO}_{2}$, vol. \% & 0.2 \\
\hline Humidity, \% & 100 \\
\hline Moisture content, $\mathrm{g} / \mathrm{m}^{3}$ & 3 \\
\hline Hydrocarbons, $\%$ & up to 50 \\
\hline \multicolumn{2}{|c|}{ Composition of associated gas (in \%): } \\
\hline $\mathrm{CH}_{4}$ & 60.55 \\
\hline $\mathrm{C}_{2} \mathrm{H}_{6}$ & 8.25 \\
\hline $\mathrm{C}_{3} \mathrm{H}_{3}$ & 16.58 \\
\hline$i-\mathrm{C}_{4} \mathrm{H}_{10}$ & 2.52 \\
\hline$n-\mathrm{C}_{4} \mathrm{H}_{10}$ & 6.30 \\
\hline methylpentane & residue \\
\hline $\mathrm{H}_{2} \mathrm{~S}$ & $20-50 \mathrm{mg} / \mathrm{l}$ \\
\hline Density at $20,40^{\circ} \mathrm{C}$ & $1.16 ; 0.963 \mathrm{~g} / 1$ \\
\hline
\end{tabular}

To study the temperature and pressure influence and the nature of the water-oil mixture, the formation fluid directly from the productive horizons of the oil field was used (Tables 1, 2). Both the products of hydrate formations and the result of their interaction with the steel surface of tubing and pressure chambers were studied. At the same time, as a result of the interaction of the corrosion-active medium with the surface of the tubing and the pressure chamber, sulfides and oxides of iron are formed, which were not taken into account in the study of hydrate formations. In addition, the products of asphalt-resin-paraffin deposits on the tubing walls and pressure chamber surface, which in some cases were present, but in very small quantities (less than $5 \%$ wt.), were not specifically studied. Therefore, they were neglected when processing the measurement results.

\section{2. Research methods of hydrate formations and} iron oxides

The method for studying hydrate formations and iron (Fe) oxides was as follows. After loading a sample of the production string pipe, welded at both ends, to which textolite gaskets were attached, into the pressure chamber, the pressure chamber was filled with reservoir water-oil mixture. Reservoir fluid was taken directly from the wells of the oil field, the chemical composition of which is given in Table 1 and 2, characterized by a high degree of hydrate formation and iron ( $\mathrm{Fe}$ ) oxides in the annulus. After sealing the pressure chamber, experiments were performed, the duration of which was kept constant and equal to 24 hours (according to the recommendations of the International Association of Corrosion Engineers - NACE). In this case, the temperature was kept constant, while the pressure was changed from 0.1 to $60 \mathrm{MPa}$. To study the effect of temperature, similar operations were performed at constant pressure and different temperatures varying from -15 to $+60{ }^{\circ} \mathrm{C}$. At the end of each experiment, the tubing sample and the pressure chamber surface were cleaned of deposits with a special scraper, and the water-oil mixture was poured through a metal sieve into a container.

Separation of hydrate formations from sulfide and oxide compounds was performed using a magnet wrapped in cellophane. Since hydrate formations are not sensitive to the magnetic field, after removing sulfides and iron oxides, they were poured into a measuring cup for weighing on electronic scales (measurement accuracy is $0.001 \mathrm{~g}$ ), and then the proportion of hydrate formations in the total mass of deposits was determined.

As a reference measurement, we took the basic option pressure $1 \mathrm{MPa}$, temperature $-15{ }^{\circ} \mathrm{C}$. In this case, the mass of hydrate formations averaged $30 \%$ of the total mass of deposits (sulfides and iron oxides, hydrate formations and asphalt-resin-paraffin deposits). The measurement results were entered into a computer for processing. A total of 120 experiments were performed.

In the process of testing the method on the laboratory installation, it was found that asphalt-resin-paraffin deposits are not formed during the experiment $(24 \mathrm{~h})$ and therefore do not make an error in the measurement results. The reproducibility of the experimental results is $85-95 \%$, the measurement error in the proposed method does not exceed $10 \%$. Data processing was performed using the methods of correlation, dispersion and regression analysis, which allowed making a comparative analysis of the formation of hydrate formations and iron $(\mathrm{Fe})$ oxides in the annular space of oil wells.

As experimental samples, tubing with a diameter of $73 \times 5.5 \mathrm{~mm}$, made of steel grade $36 \mathrm{G} 2 \mathrm{C}$, which is widely used at the fields of Ukraine, was used. Reservoir-watered oil was collected in a tank directly at the well outlet.

\section{Results of the study of hydrate formations and iron oxides}

\section{1. Development of an experimental installation}

The laboratory installation (Fig. 1) consists of a cylindrical pressure chamber 2, outside of which there is a cooling jacket 3 , in which, if necessary, liquid nitrogen is poured through a special device 12. Liquid nitrogen is 
drained at the end of the experiment through the valve 13. The pressure chamber 2 with the cooling jacket 3 is placed in the furnace 1 with thermal and electrical insulation. Inside the pressure chamber, a tube 4 with an electric heater 23 is welded asymmetrically to the bottom, which is switched on when liquid nitrogen is poured into the cooling jacket (at this time the oven is switched off). Temperature conditions in the pressure chamber are controlled by an automatic electric heating system, which includes an autotransformer with an ammeter and a voltmeter 16 , a set of thermocouples $\mathrm{TC}_{1}-\mathrm{TC}_{3}$, electronic potentiometers 8 and 15. Pressure conditions in the pressure chamber are provided by a pump BP 10, connected pulse tube 18 with a nipple 9; the pressure is controlled by a manometer M 26 . The studied objects (coils of production string tubes $1.4 \mathrm{~m}$ long) are placed in the pressure chamber, hermetically sealed by the cover 5 and squeezing bolts 6 . To prevent the influence of the upper and lower pressure chamber walls 21,25 on the measurement results, the walls are closed by an insulating (textolite) gasket 7 . Loading and unloading of the research objects - samples of tubing and formation water-oil-gas liquid 20, are carried out in an inclined position of the pressure chamber, which is fixed on the frame 14, which allows rotating the chamber around the axis of the pins 22. To prevent air from entering the investigated water-oil mixture with increasing pressure, the inner lid 24 is placed in the pressure chamber, which under pressure moves up and down the four grooves 11, milled along the forming shell of the pressure chamber. The end part of the auxiliary cover also has a groove 19 into which the sealing ring is inserted. The results of testing the method showed no significant increase in the oxygen content in the water-oil environment due to air injection into the pressure chamber.
Data on the measured parameters (temperature and pressure) are sent to the computing complex CC 17. Other information is also entered there, in particular, the volume of the investigated liquid phase, gravimetric measurement data, etc. The computing complex includes a computer, a graphics device, a digital printing device and peripherals.

The installation is made of standard modular units, easily dismantled, and therefore can be used in stationary and mobile versions (for example, in the field). The installation allows studying hydrate formation in a wide range of pressure (0.1$120 \mathrm{MPa}$ ) and temperature (from -20 to $+80{ }^{\circ} \mathrm{C}$ ). Data on the measured parameters (temperature and pressure) are sent to the computing complex. The schematic diagram of the installation can fully approximate the conditions of hydrate formation and iron oxides to the actual well processes and characteristics.

\section{2. Statistical results of studying hydrate formations} and iron oxides

The results of the experiments are shown in Fig. 2 and 3, which make it possible to determine the conditions necessary for hydrate formation and iron $(\mathrm{Fe})$ oxides.

Thus, if the temperature varies from 0 to $-15^{\circ} \mathrm{C}$, the most favorable conditions for hydrate formation are created at pressures from 0.1 to $1 \mathrm{MPa}$. If the pressure is reduced $(0.1 \ldots$ $0.8 \mathrm{MPa}$ ), the hydrate formation conditions occur at low temperatures (from -5 to $-15{ }^{\circ} \mathrm{C}$ ). If the pressure is equal to $1 \mathrm{MPa}$, conditions for maximum hydrate formation are created only in the temperature range from -15 to $+15^{\circ} \mathrm{C}$. With an increase in temperature from 20 to $40{ }^{\circ} \mathrm{C}$, favorable preconditions for hydrate formations can be realized only at pressures of 5-40 MPa, although their probability does not exceed $40-50 \%$. In the maximum temperature range of $40-60{ }^{\circ} \mathrm{C}$, hydrates can be formed, although with a small probability $(10-20 \%)$, only at elevated pressures of $40-60 \mathrm{MPa}$.

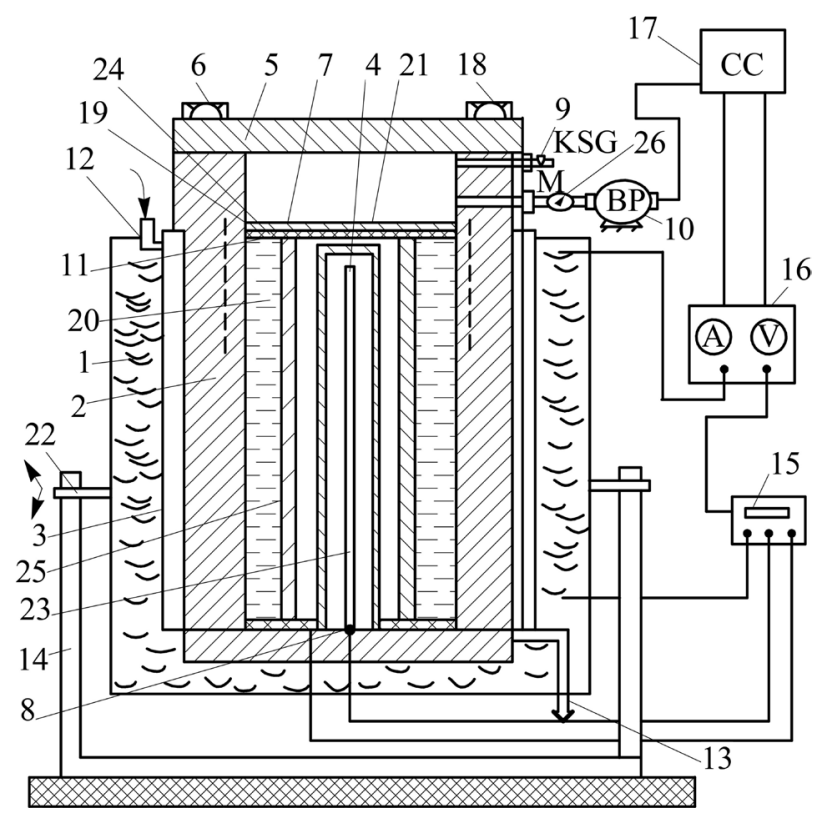

Fig. 1. Schematic diagram of the experimental installation: 1 - furnace; 2 - cylindrical pressure chamber; 3 - cooling jacket; 4 - tube; 5 - cover; 6 - squeeze bolts; 7 - insulation (textolite) gasket; 8,15 - electronic potentiometers;

9 - nipple (KSG - nipple model); 10 - booster pump (BP); 11 - grooves; 12 - special nitrogen filling device; 13 - valve; 14 - frame; 16 - automatic electric heating system; 17 -computing complex (CC); 18 - pulse tube;

19 - groove; 20 - research objects (samples of tubing and formation water-oil-gas liquid);

21, 25 - upper and lower pressure chamber walls; 22 - pins; 23 - electric heater; 24 - inner lid; 26 - manometer (M) 


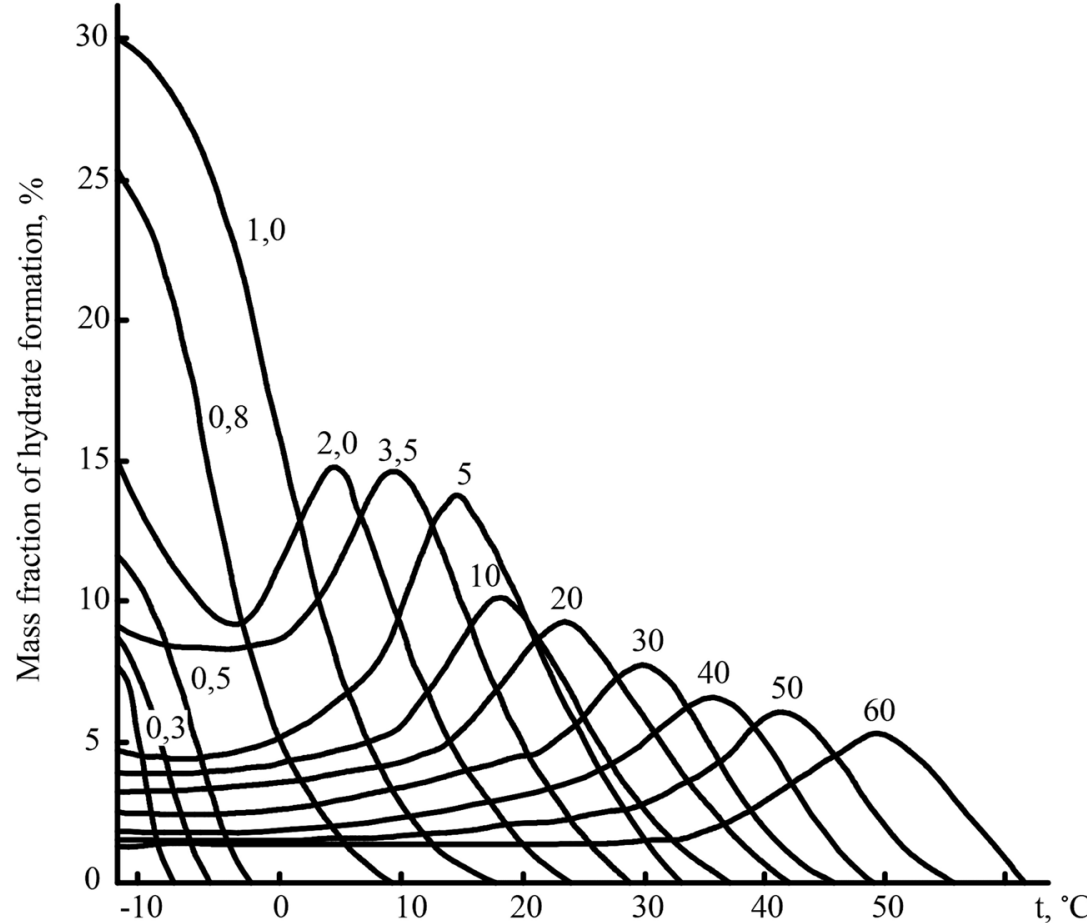

Fig. 2. Graphs of the mass fraction of hydrate formations and iron ( $\mathrm{Fe}$ ) oxides against temperature: the figures on the curves are pressure values in $\mathrm{MPa}([6])$

The data in Fig. 3 clearly illustrate three zones of hydrate formation depending on the temperature-pressure ratio, characterized by different probabilities of hydrate formation. Here are also graphs of hydrate formations of the water-oilgas mixture and separately the gas released from oil and water vapor, obtained by the calculation in [6].

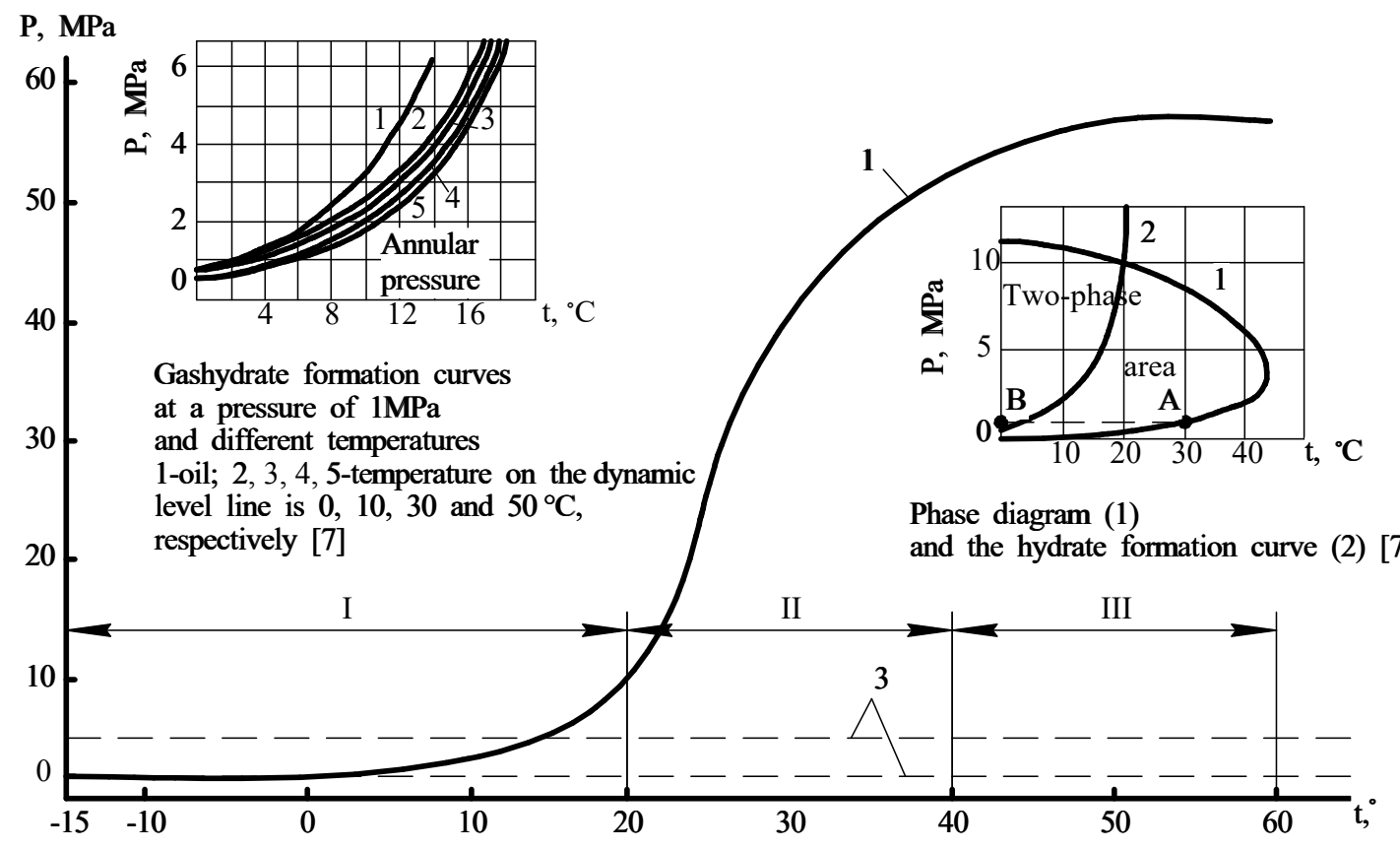

Fig. 3. Graphs of the hydrate formation curve (1) in the annulus of the oil well: zone I - maximum probability of hydrate formation (90-100 \%);

II - average probability of hydrate formation (40-50\%);

III - minimum probability of hydrate formation (10-20\%); 3 - lines of pressure-temperature conditions
6. Discussion of the results of studying hydrate formations and iron oxides in the well-proximal conditions

Comparison of data in the temperature and pressure range indicates their convergence, which confirms the adequacy of the developed method to the results of thermodynamic calculations of the oil-gas-hydrate phase equilibrium (Fig. 3). It should be noted that in the zone of the dynamic (static) level line in the well $\left(t=-5 \ldots+30{ }^{\circ} \mathrm{C}\right.$, $P=1 \ldots 5 \mathrm{MPa})$, as well as in the zones of intense condensation, favorable pressure-temperature conditions for intense hydrate formation are created (Fig. 2). This is confirmed by literature data and the results of practical observations [6, 7]. In addition, it is important to note the experimentally confirmed fact, known from the literature and present in laboratory studies, that the composition of hydrate formations changes with increasing temperature and pressure. This phenomenon is caused by the high content of gas ingredients. This must be taken into account when choosing effective reagents that help dissolve hydrate formations and remove them from the surface of downhole equipment.

It is known $[6,7]$ that the conditions of hydrate formation in the annulus are determined by the phase equilibrium on the dynamic level line at an appropriate temperature and pressure. 
The possible range of temperature and pressure in the annulus of the well at the depth of the dynamic level may not change much, but this interval is taken with some expansion. This allows considering situations involving oil heating of the tubing, from where heat is transferred to the space between the tubing and the casing, which causes an increase in pressure. Also, temperature and pressure may change due to a decrease in the annular pressure as a result of fluctuations in the dynamic level associated with pressure in the bottomhole zone, pump operation and other reasons. The increase in pressure in the annular space of the well may occur due to a thermal phenomenon, which consists in a possible significant pressure increase as a result of heating the fluids in the well space. This condition is common to all production wells.

The results of the study should be used taking into account the composition of well products and the capabilities of laboratory equipment. The installation allows studying hydrate formation in a wide range of pressure (0.1-120 MPa) and temperature (from -20 to $+80^{\circ} \mathrm{C}$ ).

\section{Conclusions}

1. The developed laboratory equipment - an experimental installation containing a technological unit and an information-measuring system, allows modeling the conditions of hydrate formation and iron oxides close to real well processes. This makes it possible to study hydrate formation in a wide range of temperature and pressure due to the presence of a pressure chamber with an electric heater and a cooling jacket with the ability to supply liquid nitrogen. Thus, the design of the installation allows using it both in laboratory, and field conditions.

2. The studies have made it possible to determine the conditions necessary for hydrate formation and iron $(\mathrm{Fe})$ oxides in the range of temperature from -15 to $+60{ }^{\circ} \mathrm{C}$ and pressure from 0 to $60 \mathrm{MPa}$. It is determined that the most favorable conditions for the formation of hydrate deposits are the pressure $0.1-1 \mathrm{MPa}$ and temperature from -5 to $-15{ }^{\circ} \mathrm{C}$

\section{References}

1. Akhfash, M., Aman, Z. M., Ahn, S. Y., Johns, M. L., May, E. F. (2016). Gas hydrate plug formation in partially-dispersed water-oil systems. Chemical Engineering Science, 140, 337-347. doi: http://doi.org/10.1016/j.ces.2015.09.032

2. Zhang, D., Huang, Q., Wang, W., Li, H., Zheng, H., Li, R. et. al. (2021). Effects of waxes and asphaltenes on $\mathrm{CO}_{2}$ hydrate nucleation and decomposition in oil-dominated systems. Journal of Natural Gas Science and Engineering, 88, 103799. doi: http:// doi.org/10.1016/j.jngse.2021.103799

3. Boiko, V. S., Boiko, R. V. (2010). Vydobuvannia i transportuvannia hidratoutvoriuvalnykh pryrodnykh i naftovykh haziv. IvanoFrankivsk: Vyd.-vo «Nova Zoria», 747.

4. Fink, J. (2021). Gas hydrate control. Petroleum Engineer's Guide to Oil Field Chemicals and Fluids. Elsevier Inc., 531-610. doi: http://doi.org/10.1016/b978-0-323-85438-2.00013-x

5. Bai, Y., Bai, Q. (2019). Hydrates. Subsea Engineering Handbook. Elsevier Inc., 409-434. doi:10.1016/b978-0-12-812622-6.00015-4

6. Vyatchinin, M. G., Pravednikov, N. K., Batalin, O. Yu. et. al. (1998). Usloviya i zony gidratoobrazovaniya v zatrubnom prostranstve neftyanoy skvazhiny. Neftyanoe khozyaystvo, 2, 56-57.

7. Vyatchinin, M. G., Pravednikov, N. K., Batalin, O. Yu. et. al. (2001). Zakonomernosti gidratoobrazovaniya v zatrubnom prostranstve neftyanoy skvazhiny. Neftyanoe khozyaystvo, 4, 54-57.

8. Greaves, D., Boxall, J., Mulligan, J., Sloan, E. D., Koh, C. A. (2008). Hydrate formation from high water content-crude oil emulsions. Chemical Engineering Science, 63 (18), 4570-4579. doi: http://doi.org/10.1016/j.ces.2008.06.025

9. Maganov, R., Vakhitov, G., Vafina, N. (2000). Optimalnaya tekhnologiya borby s gidratoparafinovymi otlozheniyami. Neft Rossii, 3, 96-99.

10. Vyatchinin, M. G., Batalin, O. Yu., Schepkina, N. E. (2000). Opredelenie rezhimov i zon gidratoobrazovaniya v neftyanykh skvazhinakh. Neftyanoe khozyaystvo, 7, 38-44.

11. Liu, Y., Shi, B., Ding, L., Ma, Q., Chen, Y., Song, S. et. al. (2019). Study of hydrate formation in water-in-waxy oil emulsions considering heat transfer and mass transfer. Fuel, 244, 282-295. doi: http://doi.org/10.1016/j.fuel.2019.02.014

12. Zhong, Y., Rogers, R. E. (2000). Surfactant effects on gas hydrate formation. Chemical Engineering Science, 55 (19), $4175-4187$. doi: http://doi.org/10.1016/s0009-2509(00)00072-5

13. Davies, S. R., Boxall, J. A., Koh, C., Sloan, E. D., Hemmingsen, P. V., Kinnari, K. J., Xu, Z.-G. (2009). Predicting Hydrate-Plug Formation in a Subsea Tieback. SPE Production \& Operations, 24 (4), 573-578. doi: http://doi.org/10.2118/115763-pa

14. Daraboina, N., Pachitsas, S., von Solms, N. (2015). Natural gas hydrate formation and inhibition in gas/crude oil/aqueous systems. Fuel, 148, 186-190. doi: http://doi.org/10.1016/j.fuel.2015.01.103

15. Vyatchinin, M. G., Batalin, O. Yu., Schepkina, N. E. (2000). Opredelenie rezhimov i zon gidratoobrazovaniya v neftyanykh skvazhinakh. Neftyanoe khozyaystvo, 7, 38-44.

16. Mansoori, G. A. Paraffin / Wax and Waxy Crude Oil. The Role of Temperature on Heavy Organics Deposition from Petroleum Fluids. Available at: http://www.uic.edu/ mansoori/Wax.and.Waxy.Crude_html 